This item was submitted to Loughborough's Research Repository by the author.

Items in Figshare are protected by copyright, with all rights reserved, unless otherwise indicated.

\title{
The effect of 14 weeks of vitamin D3 supplementation on antimicrobial peptides and proteins in athletes
}

PLEASE CITE THE PUBLISHED VERSION

http://dx.doi.org/10.1080/02640414.2015.1033642

\section{PUBLISHER}

Routledge (@ Taylor \& Francis)

VERSION

AM (Accepted Manuscript)

\section{PUBLISHER STATEMENT}

This work is made available according to the conditions of the Creative Commons Attribution-NonCommercialNoDerivatives 4.0 International (CC BY-NC-ND 4.0) licence. Full details of this licence are available at: https://creativecommons.org/licenses/by-nc-nd/4.0/

\section{LICENCE}

CC BY-NC-ND 4.0

\section{REPOSITORY RECORD}

He, Cheng-Shiun, William D. Fraser, Jason E. Tang, Kirsty Brown, Stephen Renwick, Jay Rudland-Thomas, James Teah, Ellie Tanqueray, and Michael Gleeson. 2019. "The Effect of 14 Weeks of Vitamin D3 Supplementation on Antimicrobial Peptides and Proteins in Athletes". figshare. https://hdl.handle.net/2134/17088. 
The effect of 14 weeks of vitamin $D_{3}$ supplementation on antimicrobial peptides and proteins in athletes

Cheng-Shiun $\mathrm{He}^{1}$ (c.he@lboro.ac.uk), William D Fraser ${ }^{2,3}$ (W.Fraser@uea.ac.uk), Jonathan $\operatorname{Tang}^{2}$ ( $\underline{\text { Jonathan.Tang@uea.ac.uk}), K i r s t y ~ B r o w n}{ }^{1}$ (K.Brown-11@student.lboro.ac.uk $)$, Stephen Renwick ${ }^{1}$ (S.Renwick-13@ student.lboro.ac.uk), Jay Rudland-Thomas ${ }^{1}$ (J.RudlandThomas-11@student.lboro.ac.uk), James Teah ${ }^{1}$ (J.Teah-13@student.lboro.ac.uk), Ellie Tanqueray $^{1}$ (mda09emt@sheffield.ac.uk), and Michael Gleeson ${ }^{1}$ (m.gleeson@ @lboro.ac.uk). Corresponding Author: Prof Michael Gleeson

Running title: Vitamin $\mathrm{D}_{3}$ supplementation and antimicrobial proteins

Key words: cholecalciferol, SIgA, cathelicidin, salivary flow rate

Affiliation 1:

School of Sport, Exercise and Health Sciences

Loughborough University

Loughborough

Leicestershire

LE11 3TU

United Kingdom

Tel. +44(0)1509226345 
Affiliation 2:

Norwich Medical School

Faculty of Medicine and Health Sciences

University of East Anglia

Norwich

NR4 7TJ

United Kingdom

Tel. +44(0)1603 597174

Affiliation 3:

Norfolk and Norwich University Hospital

Norwich

NR4 7UY

United Kingdom

Tel. +44(0)1603286286 


\section{Abstract}

Heavy training is associated with increased respiratory infection risk and antimicrobial proteins are important in defence against oral and respiratory tract infections. We examined the effect of 14 weeks of vitamin $\mathrm{D}_{3}$ supplementation (5000 IU/day) on the resting plasma cathelicidin concentration and the salivary secretion rates of secretory immunoglobulin A (SIgA), cathelicidin, lactoferrin and lysozyme in athletes during a winter training period. Blood and saliva were obtained at the start of the study from 39 healthy men who were randomly allocated to vitamin $\mathrm{D}_{3}$ supplement or placebo. Blood samples were also collected at the end of the study; saliva samples were collected after 7 and 14 weeks. Plasma total $25(\mathrm{OH}) \mathrm{D}$ concentration increased by $130 \%$ in the vitamin $\mathrm{D}_{3}$ group and decreased by $43 \%$ in the placebo group (both $P=0.001$ ). The percentage change of plasma cathelicidin concentration in the vitamin $\mathrm{D}_{3}$ group was higher than in the placebo group $(P=0.025)$. Only in the vitamin $\mathrm{D}_{3}$ group, the saliva SIgA and cathelicidin secretion rates increased over time (both $P=0.03$ ). A daily $5000 \mathrm{IU}$ vitamin $\mathrm{D}_{3}$ supplement has a beneficial effect in upregulating the expression of SIgA and cathelicidin in athletes during a winter training period which could improve resistance to respiratory infections. 


\section{Introduction}

Vitamin D can be obtained either from dietary sources or the epidermal layer of the skin via exposure to sunlight. Two forms of vitamin D can be obtained from dietary sources: vitamin $\mathrm{D}_{3}$ (cholecalciferol) and vitamin $\mathrm{D}_{2}$ (ergocalciferol). While vitamin $\mathrm{D}_{3}$ is found in food from animal origin, such as cod-liver oil, salmon and egg yolk, vitamin $\mathrm{D}_{2}$ is present in some plants and fungi. The vitamin $\mathrm{D}_{3}$ production from ultraviolet-mediated conversion of 7 dehydrocholesterol in the plasma membrane of skin cells provides $80-100 \%$ of the body's requirements (Lanteri et al., 2013). The endogenously synthesised vitamin $\mathrm{D}_{3}$ and dietderived $D_{2}$ and $D_{3}$ must first be hydroxylated in the liver into 25-hydroxy vitamin $D$ $(25(\mathrm{OH}) \mathrm{D})$, the main storage form. In the second hydroxylation, $25(\mathrm{OH}) \mathrm{D}$ is converted to the biologically active form, 1,25-dihydroxy vitamin $\mathrm{D}$, by 1- $\alpha$-hydroxylase in the kidney or some cells in non-renal compartments, such as cells of the immune system including T cells, B cells, macrophages and dendritic cells (Aranow, 2011).

It has recently been recognised that vitamin D is a vital mediator of innate immune responses, enhancing the antimicrobial properties of immune cells such as monocytes and macrophages (Bikle, 2009). Vitamin D is a key link between Toll-like receptor activation and antimicrobial responses in innate immunity. Following activation of the Toll-like receptor signalling cascade in the presence of microbes, vitamin D has a vital role in up-regulating the production of antimicrobial proteins (AMPs), such as cathelicidin and $\beta$-defensin (Liu et al., 2006). The biologically active, 1,25-dihydroxy vitamin $D$, binds to vitamin $D$ receptors and induces expression of vitamin D responsive genes to enhance the production of cathelicidin and $\beta$-defensin (Wang et al., 2004). These AMPs have a broad range of activities against microorganisms and may be involved in the direct inactivation of viruses through membrane destabilization (Kamen \& Tangpricha, 2010). They are produced by epithelial cells and macrophages and in the lungs are secreted into the biofilm covering the inner surface of the 
airways, thereby creating a barrier that is chemically lethal to microbes. Recently, we demonstrated that vitamin D status influences the resting plasma cathelicidin concentration and salivary SIgA secretion rate in endurance athletes during a winter training period (He et al., 2013). The plasma cathelicidin concentration in athletes with high-level vitamin D status (plasma 25(OH)D >90 nmol/L) was significantly higher than in athletes with low-level vitamin D status ( $<33 \mathrm{nmol} / \mathrm{L})$ and there was a positive correlation between the plasma 25(OH)D and cathelicidin concentrations. In addition, the averaged SIgA secretion rate during the 4-month winter period in the individuals who had relatively high vitamin D status (plasma 25(OH)D >120 nmol/L) was significantly higher than in groups having adequate, inadequate and deficient vitamin D status (adequate: $50-99.9 \mathrm{nmol} / \mathrm{L}$; inadequate: $30-49.9$ nmol/L; deficient: $<30 \mathrm{nmol} / \mathrm{L}$ ) as previously established for bone health.

Vitamin D insufficiency has been reported to be common in athletes in the United Kingdom (UK) especially when training in the winter months (Close et al., 2013; He et al., 2013; Morton et al., 2012). Two studies that assessed the vitamin D status of UK-based professional athletes (latitude $53^{\circ} \mathrm{N}$ ) reported that $62 \%$ of athletes $(38 / 61)$ including professional rugby players, soccer players and jockeys had inadequate serum total $25(\mathrm{OH}) \mathrm{D}$ concentrations $(<$ $50 \mathrm{nmol} / \mathrm{L}$ ) in the winter months (Close et al., 2013) and 65\% of elite soccer players in the English Premier League (13/20) presented with serum total 25(OH)D concentrations $<50$ nmol/L in December (Morton et al., 2012).In our previous study on a large student cohort of endurance athletes, we also found that $55 \%$ of endurance athletes $(100 / 181)$ had serum total $25(\mathrm{OH}) \mathrm{D}$ concentrations $<50 \mathrm{nmol} / \mathrm{L}$ at the end of the 4-month winter training period $(\mathrm{He}$ et al., 2013). Given that the high prevalence of insufficient vitamin D status in athletes in the UK during winter months, it seems probable that vitamin D supplementation could be desirable for athletes during this period to increase vitamin D concentrations to up-regulate the expression of AMPs and possibly reduce the risk of respiratory infections. 
The purpose of this study was to examine the effect of 14 weeks of vitamin $\mathrm{D}_{3}$ supplementation (5000 IU/day) on the resting plasma cathelicidin concentration and the salivary concentrations and secretion rates of SIgA, cathelicidin, lactoferrin and lysozyme in a population of individuals engaged in regular sport training during a winter training period.

\section{Methods}

Participants

Fifty healthy men aged $20.4 \pm 1.9$ years who were engaged in regular sports training (such as rugby, volleyball, swimming, triathlon, cycling and racquet sports) from Loughborough University, UK (latitude $53^{\circ} \mathrm{N}$ ) volunteered to participate in the study during November 2013 and their self-reported training loads (determined by a pre-screening questionnaire) averaged $11 \pm 4 \mathrm{~h} /$ week (mean $\pm \mathrm{SD}$ ). Participants were required to complete a comprehensive healthscreening questionnaire prior to starting the study and had not taken any regular medication or antibiotics in the 3 months prior to the study. All participants were fully informed about the rationale for the study and of all experimental procedures to be undertaken. Participants provided written consent to participate in the study, which had earlier received the approval of Loughborough University ethical advisory committee. Participants were enrolled after having fulfilled all inclusion criteria, and presenting none of the exclusion criteria (determined by questionnaire). Participants could be included if they were currently healthy (with no health problems or infection symptoms within the previous 2 weeks), engaged in regular sports training at least 3 sessions and at least $3 \mathrm{~h}$ of total moderate/high-intensity training time per week and were between 18-35 years of age. Participants representing one or more of the following criteria were excluded from participation: smoking or use of any medication, suffering from or had a history of cardiac, hepatic, renal, pulmonary, 
neurological, gastrointestinal, haematological or psychiatric illness. Participants were not allowed to take any other supplements, other than a daily multivitamin tablet providing no more than the Recommended Dietary Allowances of essential vitamins.

Study protocol

Information about the study was given to the participants 1-2 weeks before their first visit to the laboratory. For the first visit to the laboratory, participants arrived in the morning at 09:00-12:00 following a 3-h fast and their body mass and stature were recorded. Participants were required to abstain from any strenuous physical activity for $24 \mathrm{~h}$ before coming to the laboratory. Participants sat quietly for 10 min and completed a health-screening questionnaire and inclusion/exclusion criteria questionnaire before signing an informed consent form and providing an unstimulated saliva sample by passive dribble into a preweighed sterile collection tube for a timed period (usually $2 \mathrm{~min}$; longer was allowed if the volume of saliva collected after 2 min was insufficient). After centrifugation for 2 min at $5000 \mathrm{~g}$ to remove cells and insoluble matter, saliva samples were stored frozen at $-20^{\circ} \mathrm{C}$ prior to analysis. Subsequently, a resting venous blood sample $(6 \mathrm{ml})$ was obtained by venepuncture from an antecubital forearm vein into a vacutainer tube (Becton Dickinson, Oxford, UK) containing $\mathrm{K}_{3}$ EDTA and haematological analysis was immediately carried out (including haemoglobin, haematocrit and total and differential leukocyte counts) using an automated cell-counter ( $\mathrm{A}^{\mathrm{c}} . \mathrm{T}^{\mathrm{TM}} 5$ diff haematology analyser, Beckman Coulter, High Wycombe, UK). Participants had to have haematology variables within the normal reference range to be included in the study. The remaining EDTA blood was centrifuged for $10 \mathrm{~min}$ at $1500 \mathrm{~g}$ and $4^{\circ} \mathrm{C}$ and the plasma stored at $-20^{\circ} \mathrm{C}$ prior to analysis. 
The participants were randomly allocated to an intervention (vitamin $\mathrm{D}_{3}$ supplement) group or placebo group for 14 weeks in a double-blind fashion. The vitamin $\mathrm{D}_{3}$ group received a daily supplement of $5000 \mathrm{IU}$ of vitamin $\mathrm{D}_{3}$ in capsule form, whereas the placebo group received a visually identical cellulose placebo capsule (Bio-Tech Pharmacal, Arkansas, USA). Participants were given a 7-week supply of vitamin $\mathrm{D}_{3}$ or placebo capsules and attended the laboratory again after 7 weeks to get another 7-week supply of supplement. Participants were also asked to fill in a standard short form of International Physical Activity Questionnaire (IPAQ; http://www.ipaq.ki.se/downloads.htm) at weekly intervals, thus providing the quantitative information on training loads in metabolic equivalents (MET)-h/week (Craig et al., 2003).

Participants attended the laboratory after 7 and 14 weeks following a 3-h fast and their body mass was recorded again. Participants were also required to abstain from any strenuous physical activity for $24 \mathrm{~h}$ before coming to the laboratory. Blood samples were collected again at the end of the study and unstimulated saliva samples were collected after 7 and 14 weeks. A total of 39 participants completed the study and provided sufficient blood for routine haematology and vitamin D status analysis at the start and end of the study and sufficient saliva $(1 \mathrm{~mL})$ for analysis of AMPs on all 3 occasions.

Plasma analysis

Plasma samples were analysed for total $25(\mathrm{OH}) \mathrm{D}$ and cathelicidin concentrations. Total $25(\mathrm{OH}) \mathrm{D}$ (the sum of the 25-hydroxy metabolites of $\mathrm{D}_{2}$ and $\mathrm{D}_{3}$ ) in EDTA plasma was determined after a maximum of 8 months in storage (with no previous freeze-thaw cycles) using a high pressure liquid chromatography - tandem mass spectrometer (Waters Acuity, Manchester, UK) as described by Owens et al. (2014) and recommended by Fraser \& Milan, 
(2013) and Wallace, Gibson, de la Hunty, Lamberg-Allardt, \& Ashwell (2010).

Measurements were performed in a laboratory meeting the performance target set by the Vitamin D External Quality Assessment Scheme Advisory Panel for 25(OH)D assays.

EDTA plasma with 20X dilution was assayed in duplicate for cathelicidin concentration using a commercially available ELISA kit (Hycult Biotech, Uden, The Netherlands) according to the manufacturers' instructions. The intra-assay CV was $\pm 2.4 \%$ across a working range of $0.1-100 \mu \mathrm{g} / \mathrm{L}$.

Saliva analysis

Saliva samples were analysed in duplicate for the salivary AMPs. The saliva volume collected was estimated by weighing and the saliva flow rate was calculated. Saliva samples with 5X dilution were analysed for SIgA using an ELISA kit (Salimetrics, Philadelphia, USA). Salivary lactoferrin and lysozyme were analysed using commercially available ELISA kits (Calbiochem, USA and Biomedical Technologies, USA, respectively) with 500X dilution. Saliva samples were also assayed for cathelicidin concentration using a commercially available ELISA kit (Hycult Biotech, Uden, The Netherlands). Secretion rates for each of the salivary AMPs were calculated as the multiple of the saliva flow rate and AMP concentration. All saliva assays were carried out in duplicate. The intra-assay CVs for all the assays were $<4 \%$ across a working range of 2.5-600 mg/L for SIgA, 1.6-100 $\mu \mathrm{g} / \mathrm{L}$ for lactoferrin, $0.78-50 \mu \mathrm{g} / \mathrm{L}$ for lysozyme and $0.1-100 \mu \mathrm{g} / \mathrm{L}$ for cathelicidin.

Statistical analysis 
The Shapiro-Wilk test was used to determine if data sets were normally distributed. Anthropometric, self-reported training load (h/week), average IPAQ scores (MET-h/week) and haematological variables were compared between the vitamin $\mathrm{D}_{3}$ and placebo groups using unpaired $t$ tests for normally distributed data or nonparametric Mann-Whitney $U$ test for non-normally distributed data. Plasma total $25(\mathrm{OH}) \mathrm{D}$ and cathelicidin concentrations at the start and end of the study were assessed between the vitamin $\mathrm{D}_{3}$ and placebo groups using nonparametric Wilcoxon signed ranks test and Mann-Whitney U test. The percentage change of plasma cathelicidin concentration during the study period was also compared between two groups using nonparametric Mann-Whitney $\mathrm{U}$ test. The changes in the concentrations and secretion rates of salivary AMPs as well as the salivary flow rates over the 14 weeks of the study in the vitamin $\mathrm{D}_{3}$ and placebo groups were assessed by two-way ANOVA or nonparametric Friedman tests with post hoc Dunn's test and Mann-Whitney U test. Data are presented as mean $( \pm \mathrm{SD})$ for data sets that were normally distributed; for data sets that were not normally distributed, the median and interquartile range are shown. The accepted level of significance was $P<0.05$. Where appropriate, effect sizes were calculated using Cohen's d (G*Power Version 3.1).

\section{Results}

Adherence to the study

Thirty nine participants (vitamin $\mathrm{D}_{3}: \mathrm{n}=20$; placebo: $\mathrm{n}=19$ ) completed the study and provided sufficient blood for routine haematology and analysis of $25(\mathrm{OH}) \mathrm{D}$ and cathelicidin concentrations on 2 occasions and sufficient saliva for analysis of AMPs on all 3 occasions. Reasons for dropout were given as foreign travel $(\mathrm{N}=3)$, injury $(\mathrm{N}=6)$ or due to undisclosed reasons $(\mathrm{N}=2)$. 
Baseline characteristics and physical activity levels

There were no significant differences in baseline anthropometrics or haematological variables between the vitamin $\mathrm{D}_{3}$ and placebo groups (Table 1). Analysis of the IPAQ questionnaires indicated that the weekly training loads during the study period were relatively stable within the vitamin $\mathrm{D}_{3}$ and placebo groups. The training loads averaged over the study period were not significantly different between the vitamin $\mathrm{D}_{3}$ and placebo group (Table 1). Median (interquartile range) training loads were $69.0(49.3-80.3)$ MET-h/week in the vitamin $\mathrm{D}_{3}$ group which is equivalent to about $11.4 \mathrm{~h}$ of moderate-vigorous activity per week and 78.2 (47.6-112.0) MET-h/week in the placebo group which is equivalent to about $12.9 \mathrm{~h}$ of moderate-vigorous activity per week.

Plasma total 25(OH)D and cathelicidin concentrations

The median plasma total $25(\mathrm{OH}) \mathrm{D}$ concentration increased from 54.5 to $125.5 \mathrm{nmol} / \mathrm{L}$ at week 14 in the vitamin $\mathrm{D}_{3}$ group $(P=0.001$, effect size=2.71) and decreased from 57.0 to 32.5 $\mathrm{nmol} / \mathrm{L}$ in the placebo group at 14 weeks $(P=0.001$, effect size $=0.95)($ Table 2$)$. At the end of the study there was a significant difference between groups $(P<0.001$, effect size $=4.05)$. Although the median plasma cathelicidin concentration increased in both groups (vitamin $\mathrm{D}_{3}$ : 29.5 to $34.0 \mathrm{ng} / \mathrm{mL}, P=0.003$, effect size $=0.27$; placebo: 30.9 to $33.6 \mathrm{ng} / \mathrm{mL}, P=0.048$, effect size $=0.16$; Wilcoxon signed ranks test) $($ Table 2), the percentage change of cathelicidin concentration in the vitamin $\mathrm{D}_{3}$ group was higher than in the placebo group (vitamin $\mathrm{D}_{3}$ : 15.0\%; placebo: 5.4\%, $P=0.025$, effect size=0.75; Mann-Whitney U test) (Figure 1). 
Salivary variables

While the concentrations of all salivary AMPs were not significantly altered over time in both vitamin $D_{3}$ and placebo groups, the salivary flow rates increased over time in the vitamin $D_{3}$ group $(P=0.022$, effect size $=0.32)$ (Table 3$)$. The resting SIgA and cathelicidin secretion rates increased over time in the vitamin $\mathrm{D}_{3}$ group (but not in the placebo group) (SIgA: 58.8, 87.2, $70.5 \mu \mathrm{g} / \mathrm{min}, P=0.026$, effect size $=0.32$; cathelicidin: $0.076,0.103,0.090 \mathrm{ng} / \mathrm{min}, P=0.030$, effect size $=0.21$; Friedman tests) (Figure $2 \mathrm{a}$ and $2 \mathrm{~b}$ ). Salivary lysozyme secretion rate increased over time in both groups (time, $P=0.002$; two-way ANOVA) but lactoferrin secretion rate was unaltered (Figure $2 \mathrm{c}$ and $2 \mathrm{~d}$ ).

\section{Discussion}

As expected, plasma total $25(\mathrm{OH}) \mathrm{D}$ concentration significantly increased in the vitamin $\mathrm{D}_{3}$ group and significantly decreased in the placebo group. The salivary SIgA and cathelicidin secretion rates significantly increased over time in the vitamin $\mathrm{D}_{3}$ group but not in the placebo group. In addition, the percentage change of plasma cathelicidin concentration in the vitamin $\mathrm{D}_{3}$ group was significantly higher than in the placebo group although plasma cathelicidin concentration significantly increased in both groups.

We demonstrated that in athletes following 14 weeks of vitamin $D_{3}$ supplementation with $5000 \mathrm{IU} /$ day there was a significant increase in the plasma total $25(\mathrm{OH}) \mathrm{D}$ concentration from 54.5 to $125.5 \mathrm{nmol} / \mathrm{L}$. This increase in total $25(\mathrm{OH}) \mathrm{D}$ is similar to a previous randomised placebo-controlled trial of 5000 IU daily vitamin $\mathrm{D}_{3}$ supplementation, where plasma 25(OH)D levels increased significantly from 29 to $103 \mathrm{nmol} / \mathrm{L}$ in the intervention group after 8 weeks of supplementation (Close et al., 2013). During the winter months, 5000 IU of 
vitamin $\mathrm{D}_{3}$ supplement daily is a possible way for athletes to elevate $25(\mathrm{OH}) \mathrm{D}$ concentrations above a mean of $100 \mathrm{nmol} / \mathrm{L}$ which some authors suggest is the optimal concentration for a number of beneficial effects (Heaney, 2011; Zittermann, 2003). It was also observed that plasma total $25(\mathrm{OH}) \mathrm{D}$ concentration significantly decreased in the placebo group from November to February probably reflecting seasonal changes and time from last effective ultraviolet exposure. Several other studies that assessed the plasma $25(\mathrm{OH}) \mathrm{D}$ concentrations of UK-based athletes have shown that there was no change or a significant decrease in the plasma $25(\mathrm{OH}) \mathrm{D}$ levels during the winter training period in athletes without vitamin $\mathrm{D}$ supplementation (Close et al., 2013; He et al., 2013; Owens et al., 2014). This is most likely due to insufficient ultraviolet radiation of appropriate wavelength $(290-315 \mathrm{~nm})$ between November and March in the UK to produce vitamin D in the skin (Webb \& Holick, 1988).

In the present study the resting salivary SIgA and cathelicidin secretion rates significantly increased over time in the vitamin $\mathrm{D}_{3}$ group. To our knowledge, this is the first report to show a significant increase in the resting salivary SIgA secretion rates after a period of vitamin $D_{3}$ supplementation. The reasons for this are still unclear, but could be related to the elevated salivary flow rates after vitamin $\mathrm{D}_{3}$ supplementation. We report that the salivary flow rates significantly increased over time in the vitamin $\mathrm{D}_{3}$ group. Several animal studies have demonstrated that vitamin D receptors are present in the parotid, submandibular and sublingual salivary glands which suggest a possible role for vitamin D in regulation of salivary secretion. This is supported by the finding that salivary flow rates were stimulated after treatment with vitamin $\mathrm{D}_{3}$ in vitamin D-deficient rats (Peterfy et al., 1988; Stumpf, 2008). Although the influence of vitamin D on salivary flow rate has not yet been demonstrated in humans, the finding that there was a significant positive correlation between plasma total $25(\mathrm{OH}) \mathrm{D}$ concentration and salivary flow rate in the endurance athlete cohort 
$(\mathrm{N}=225)$ (unpublished data in our previous study (He et al., 2013), $\mathrm{r}=0.196, P=0.003$; Pearson correlation test) might lend some support to this suggestion.

We also found that salivary cathelicidin secretion rates only significantly increased in the participants with vitamin $\mathrm{D}_{3}$ supplementation. Human cathelicidin is expressed in neutrophils, epithelial cells and salivary glands and can be detected in whole saliva (Davison et al., 2009; Murakami et al., 2002). The elevated salivary cathelicidin secretion rates might be due to the influence of $25(\mathrm{OH}) \mathrm{D}$ in the human oral epithelial cells. Human oral epithelial cells which express vitamin D receptors and 1- $\alpha$-hydroxylase have the enzymatic machinery to convert $25(\mathrm{OH}) \mathrm{D}$ to 1,25 -dihydroxy vitamin $\mathrm{D}$ and it has been demonstrated that $25(\mathrm{OH}) \mathrm{D}$ can induce expression of the vitamin D responsive genes to enhance the production of cathelicidin by binding to vitamin D receptors in dose-related manner in human oral keratinocytes (Wang et al., 2013).

Our results indicate that 5000 IU of vitamin D3 supplement daily could have a beneficial effect in up-regulating plasma cathelicidin. We found that the percentage change of cathelicidin concentration in the vitamin $\mathrm{D}_{3}$ group was significantly higher than in the placebo group, although plasma cathelicidin concentration significantly increased in both groups from November to March. The reason for the increase of plasma cathelicidin concentration in the placebo group is unclear, but could be related to the likely higher respiratory infection incidence over the winter months as cathelicidin production is increased following pathogen exposure and Toll-like receptor activation (Bucki et al., 2010). Moreover, there was a similar result in another vitamin $\mathrm{D}_{3}$ supplement study in which 25 healthy participants with plasma 25(OH)D concentration less than $80 \mathrm{nmol} / \mathrm{L}$ ingested 50,000 IU vitamin $\mathrm{D}_{3}$ every other day, for 5 days, and a statistically significant increase of circulating cathelicidin concentration was only found in participants with $25(\mathrm{OH}) \mathrm{D}$ levels increasing more than $80 \mathrm{nmol} / \mathrm{L}$ after the vitamin $\mathrm{D}_{3}$ treatment (Bhan et al., 2011). In our study, we also 
found a significant increase of plasma cathelicidin concentration in the vitamin $\mathrm{D}_{3}$ group although there were only 5 participants with $25(\mathrm{OH}) \mathrm{D}$ levels increasing more than $80 \mathrm{nmol} / \mathrm{L}$ after supplementation. It has been reported that patients with the lowest circulating concentrations of cathelicidin undergoing dialysis are at a greater than two-fold increased risk of death from infectious causes (Gombart et al., 2009). Given the observed associations of circulating cathelicidin concentrations and infection-associated mortality in human studies, a high dose of vitamin $\mathrm{D}_{3}$ supplementation might be clinically useful in the populations that may be more at risk of infection due to occupational or lifestyle stress (e.g. athletes and military personnel).

Recently, it has been suggested that several salivary AMPs, such as SIgA and cathelicidin, might be associated with the incidence of upper respiratory tract infection. Previous studies have shown an inverse relationship between SIgA values and upper respiratory tract infection prevalence and low SIgA values have been reported to be associated with increased incidence of upper respiratory tract infection in athletes (Fahlman \& Engels, 2005; Gleeson et al., 1999, 2012; Neville et al., 2008). A one-year follow-up study has reported that the number of upper respiratory tract infection episodes was negatively correlated with salivary cathelicidin levels (Usui et al., 2012). Further studies are still needed to establish if the enhancement of salivary SIgA and cathelicidin secretion after vitamin D supplementation could reduce the risk of upper respiratory tract infection in athletes.

In conclusion, $5000 \mathrm{IU}$ of vitamin $\mathrm{D}_{3}$ supplementation daily appears to have a beneficial effect in up-regulating the expression of SIgA and cathelicidin in athletes during a winter training period. Vitamin D supplementation, therefore, could have a positive effect on immune function and lead to decreased incidence of respiratory infections. Further research in a substantially larger athlete cohort is needed to determine this possibility. 


\section{References}

Aranow, C. (2011). Vitamin D and the immune system. Journal of investigative medicine, $59(6), 881-886$.

Bucki, R., Leszczyńska, K., Namiot, A., \& Sokołowski, W. (2010). Cathelicidin LL-37: a multitask antimicrobial peptide. Archivum immunologiae et therapiae experimentalis, $58(1), 15-25$.

Bhan, I., Camargo, C. A., Jr., Wenger, J., Ricciardi, C., Ye, J., Borregaard, N., et al. (2011). Circulating levels of 25-hydroxyvitamin D and human cathelicidin in healthy adults. Journal of Allergy and Clinical Immunology, 127(5), 1302-1304 e1301.

Bikle, D. (2009). Nonclassic actions of vitamin D. The Journal of Clinical Endocrinology \& Metabolism, 94(1), 26-34.

Close, G. L., Russell, J., Cobley, J. N., Owens, D. J., Wilson, G., Gregson, W., et al. (2013). Assessment of vitamin D concentration in non-supplemented professional athletes and healthy adults during the winter months in the UK: implications for skeletal muscle function. Journal of sports sciences, 31(4), 344-353.

Craig, C. L., Marshall, A. L., Sjostrom, M., Bauman, A. E., Booth, M. L., Ainsworth, B. E., et al. (2003). International physical activity questionnaire: 12-country reliability and validity. Medicine and science in sports and exercise, 35(8), 1381-1395.

Davison, G., Allgrove, J., \& Gleeson, M. (2009). Salivary antimicrobial peptides (LL-37 and alpha-defensins HNP1-3), antimicrobial and IgA responses to prolonged exercise. European journal of applied physiology, 106(2), 277-284.

Fahlman, M. M., \& Engels, H. J. (2005). Mucosal IgA and URTI in American college football players: a year longitudinal study. Medicine and science in sports and exercise, 37(3), 374-380. 
Fraser, W.D., \& Milan, A.M. (2013). Vitamin D assays: past and present debates, difficulties, and developments. Calcified tissue international, 92(2), 118-127.

Gleeson, M., Bishop, N., Oliveira, M., McCauley, T., Tauler, P., \& Muhamad, A. S. (2012). Respiratory infection risk in athletes: association with antigen-stimulated IL-10 production and salivary IgA secretion. Scandinavian journal of medicine \& science in sports, 22(3), 410-417.

Gleeson, M., McDonald, W.A., Pyne, D.B., Cripps, A.W., Francis, J.L., Fricker, P.A., \& Clancy, R.L. (1999). Salivary IgA levels and infection risk in elite swimmers. Medicine and Science in Sports and Exercise, 31(1), 67-73, 1999.

Gombart, A. F., Bhan, I., Borregaard, N., Tamez, H., Camargo, C. A., Jr., Koeffler, H. P., et al. (2009). Low plasma level of cathelicidin antimicrobial peptide (hCAP18) predicts increased infectious disease mortality in patients undergoing hemodialysis. Clinical infectious diseases, 48(4), 418-424.

He, C. S., Handzlik, M., Fraser, W. D., Muhamad, A., Preston, H., Richardson, A., et al. (2013). Influence of vitamin D status on respiratory infection incidence and immune function during 4 months of winter training in endurance sport athletes. Exercise immunology review, 19, 86-101.

Heaney, R. P. (2011). Assessing vitamin D status. Current Opinion in Clinical Nutrition \& Metabolic Care, 14(5), 440-444.

Kamen, D. L., \& Tangpricha, V. (2010). Vitamin D and molecular actions on the immune system: modulation of innate and autoimmunity. Journal of Molecular Medicine, $88(5), 441-450$.

Lanteri, P., Lombardi, G., Colombini, A., \& Banfi, G. (2013). Vitamin D in exercise: physiologic and analytical concerns. Clinica Chimica Acta, 415, 45-53. 
Liu, P. T., Stenger, S., Li, H., Wenzel, L., Tan, B. H., Krutzik, S. R., et al. (2006). Toll-like receptor triggering of a vitamin D-mediated human antimicrobial response. Science, $311(5768), 1770-1773$.

Morton, J. P., Iqbal, Z., Drust, B., Burgess, D., Close, G. L., \& Brukner, P. D. (2012). Seasonal variation in vitamin D status in professional soccer players of the English Premier League. Applied Physiology, Nutrition, and Metabolism, 37(4), 798-802.

Murakami, M., Ohtake, T., Dorschner, R. A., \& Gallo, R. L. (2002). Cathelicidin antimicrobial peptides are expressed in salivary glands and saliva. Journal of dental research, 81(12), 845-850.

Neville, V., Gleeson, M., \& Folland, J. P. (2008). Salivary IgA as a risk factor for upper respiratory infections in elite professional athletes. Medicine and Science in Sports and Exercise, 40(7), 1228-1236.

Owens, D. J., Webber, D., Impey, S. G., Tang, J., Donovan, T. F., Fraser, W. D., et al. (2014). Vitamin D supplementation does not improve human skeletal muscle contractile properties in insufficient young males. European journal of applied physiology, 114(6), 1309-1320.

Peterfy, C., Tenenhouse, A., \& Yu, E. (1988). Vitamin D and parotid gland function in the rat. The Journal of physiology, 398, 1-13.

Stumpf, W. E. (2008). Vitamin D and the digestive system. European journal of drug metabolism and pharmacokinetics, 33(2), 85-100.

Usui, T., Yoshikawa, T., Orita, K., Ueda, S.-y., Katsura, Y., \& Fujimoto, S. (2012). Comparison of salivary antimicrobial peptides and upper respiratory tract infections in elite marathon runners and sedentary participants. The Journal of Physical Fitness and Sports Medicine, 1(1), 175-181. 
Wallace, A. M., Gibson, S., de la Hunty, A., Lamberg-Allardt, C., \& Ashwell, M. (2010). Measurement of 25-hydroxyvitamin D in the clinical laboratory: current procedures, performance characteristics and limitations. Steroids, 75(7), 477-488.

Wang, Q., Zhang, W., Li, H., Aprecio, R., Wu, W., Lin, Y., et al. (2013). Effects of 25hydroxyvitamin D3 on cathelicidin production and antibacterial function of human oral keratinocytes. Cellular immunology, 283(1-2), 45-50.

Wang, T. T., Nestel, F. P., Bourdeau, V., Nagai, Y., Wang, Q., Liao, J., et al. (2004). Cutting edge: 1,25-dihydroxyvitamin D3 is a direct inducer of antimicrobial peptide gene expression. The Journal of Immunology, 173(5), 2909-2912.

Webb, A. R., \& Holick, M. F. (1988). The role of sunlight in the cutaneous production of vitamin D3. Annual review of nutrition, 8, 375-399.

Zittermann, A. (2003). Vitamin D in preventive medicine: are we ignoring the evidence? British Journal of Nutrition, 89(5), 552-572. 


\section{Figure legends}

Figure 1. The percentage change of plasma cathelicidin concentration after the 14-week intervention period in the vitamin $\mathrm{D}_{3}$ supplement and placebo groups. Data are median and interquartile range. $*$ Significant difference between groups $(P=0.025$; Mann-Whitney $\mathrm{U}$ test $)$.

Figure 2. Changes in salivary secretion rates after 7 and 14 weeks of the intervention period in the vitamin $\mathrm{D}_{3}$ supplement and placebo groups for (A) SIgA, (B) cathelicidin, (C) lysozyme and (D) lactoferrin. Data are shown as the mean \pm SD (lysozyme) or the median and interquartile range (SIgA, cathelicidin and lactoferrin) as appropriate. The location of significant differences from week 0 within the vitamin $\mathrm{D}_{3}$ supplemented group only is indicated as follows: $* P<0.05$; $† P=0.05$ (Dunn's post hoc test applied when Friedman test $P<0.05)$. Significant difference from week 0 in both groups is indicated as follows: $\# P<0.05$. 
Table 1. Anthropometric, training and haematological variables in the vitamin $D_{3}$ and placebo groups at baseline and their training loads determined by IPAQ during the intervention period

\begin{tabular}{|c|c|c|c|}
\hline & Vitamin $D_{3}(n=20)$ & Placebo $(n=19)$ & $\boldsymbol{P}$ \\
\hline Age (years) & $20.1 \pm 1.7$ & $21.0 \pm 2.3$ & 0.168 \\
\hline Stature (cm) & $181.9 \pm 6.9$ & $182.2 \pm 8.0$ & 0.907 \\
\hline Body mass (kg) & $80.8 \pm 13.1$ & $80.0 \pm 11.2$ & 0.849 \\
\hline BMI $\left(\mathrm{kg} / \mathrm{m}^{2}\right)$ & $24.3 \pm 3.1$ & $24.1 \pm 2.6$ & 0.769 \\
\hline Previous training load (h/week) & $10.1 \pm 4.0$ & $11.1 \pm 4.8$ & 0.503 \\
\hline IPAQ (MET-h/week) & $69.0(49.3-80.3)$ & $78.2(47.6-112.0)$ & 0.374 \\
\hline$R B C$ count $\left(\times 10^{12} / L\right)$ & $4.8 \pm 0.3$ & $4.9 \pm 0.3$ & 0.231 \\
\hline Haematocrit (\%) & $44.1 \pm 1.9$ & $43.8 \pm 2.5$ & 0.687 \\
\hline Haemoglobin (g/L) & $148 \pm 7$ & $146 \pm 7$ & 0.546 \\
\hline Leukocyte count $\left(\mathrm{x}^{9} 0^{9} / \mathrm{L}\right)$ & $5.5 \pm 1.4$ & $5.7 \pm 1.2$ & 0.707 \\
\hline
\end{tabular}

Data are shown as the mean \pm SD or the median and interquartile range as appropriate. $P$ values are from unpaired t tests apart from IPAQ training load where the Mann-Whitney U test for nonparametric data was used. 
Table 2. Plasma total 25(OH)D and cathelicidin concentrations in the vitamin $D_{3}$ and placebo groups before and after the 14-week intervention period

\begin{tabular}{ccccc}
\hline & & Pre & Post & P \\
\hline $\begin{array}{c}\text { Total 25(OH) } \\
(\mathbf{n m o l} / \mathbf{L})\end{array}$ & Vitamin $\mathrm{D}_{3}$ & $54.5(43.2-71.0)$ & $125.5(96.8-149.5) *$ & 0.001 \\
& Placebo & $57.0(38.7-71.0)$ & $32.5(26.7-49.3)$ & 0.001 \\
\hline Cathelicidin $(\mu \mathrm{g} / \mathrm{L})$ & Vitamin $\mathrm{D}_{3}$ & $29.5(26.6-32.3)$ & $34.0(30.0-38.3)$ & 0.003 \\
& Placebo & $30.9(27.7-36.6)$ & $33.6(28.4-38.1)$ & 0.048 \\
\hline
\end{tabular}

Data are shown as the median and interquartile range for nonparametric Wilcoxon signed ranks test. Significant difference between groups: $* P<0.001$ based on Mann-Whitney U test. 
Table 3. Salivary flow rate and AMPs concentration in the vitamin $D_{3}$ and placebo groups before and after 7 and 14 weeks of the intervention

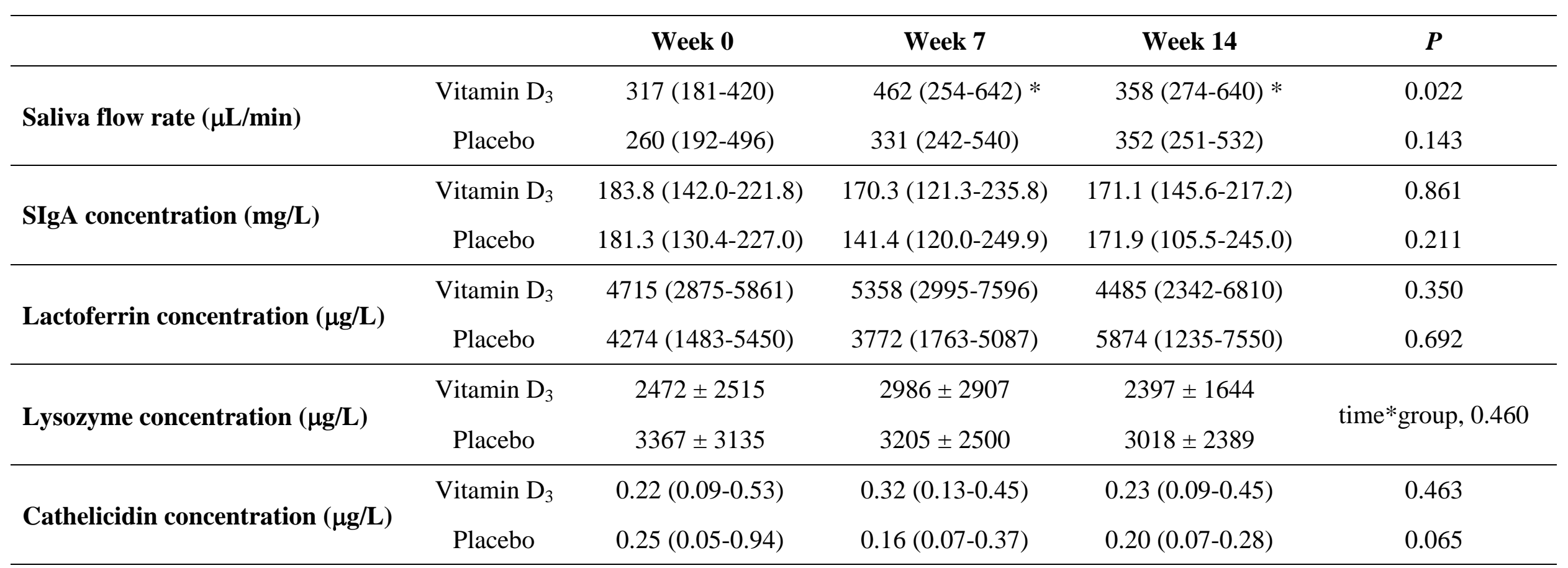

Data are shown as the mean \pm SD for two-way ANOVA or the median and interquartile range for nonparametric Friedman test with post hoc Dunn's test. The location of significant differences from week 0 within the group is indicated as follows: * $P<0.05$ (Dunn's post hoc test applied when Friedman test $P<0.05)$. 
Figure 1

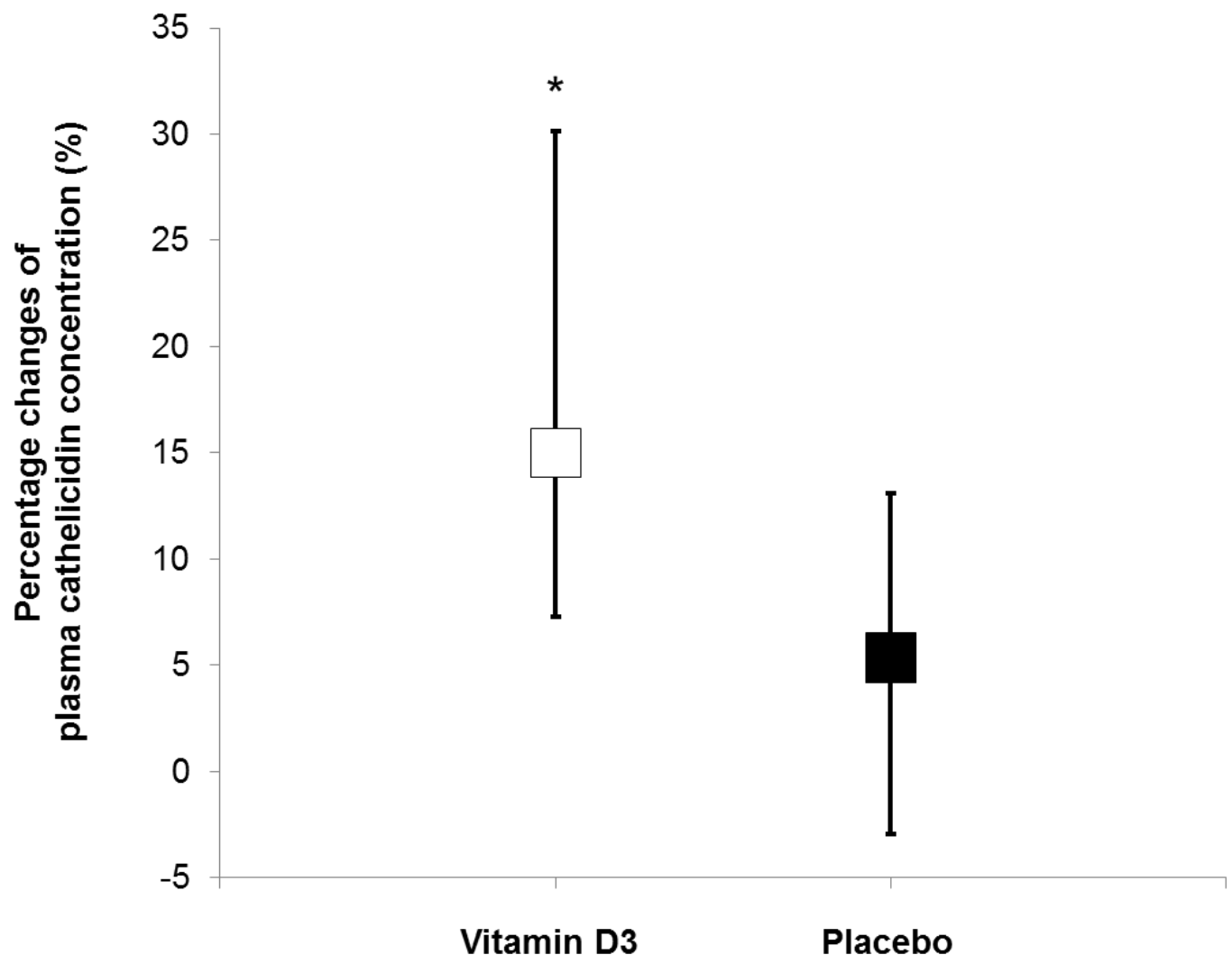


Figure 2

(A)

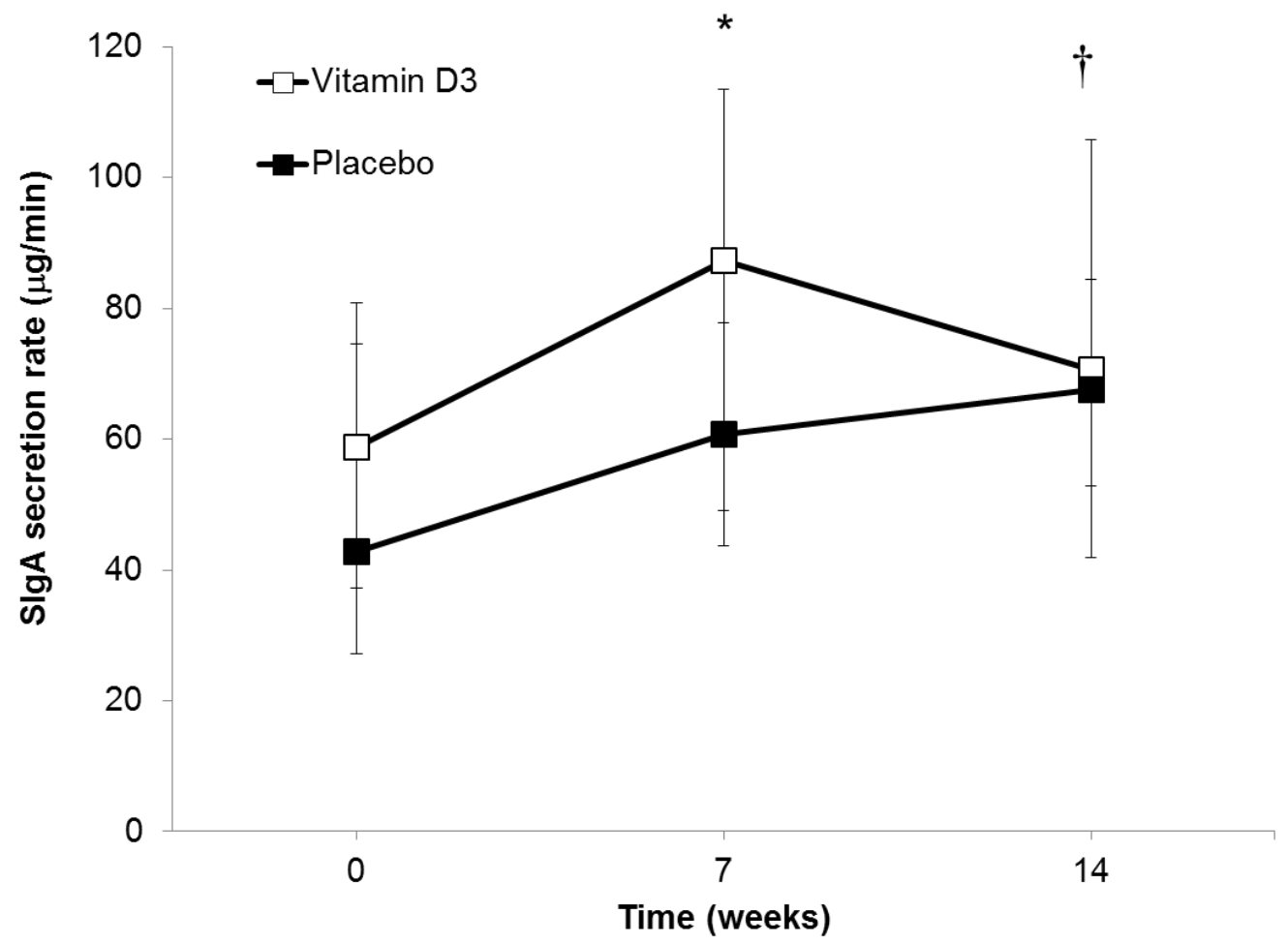

(B)

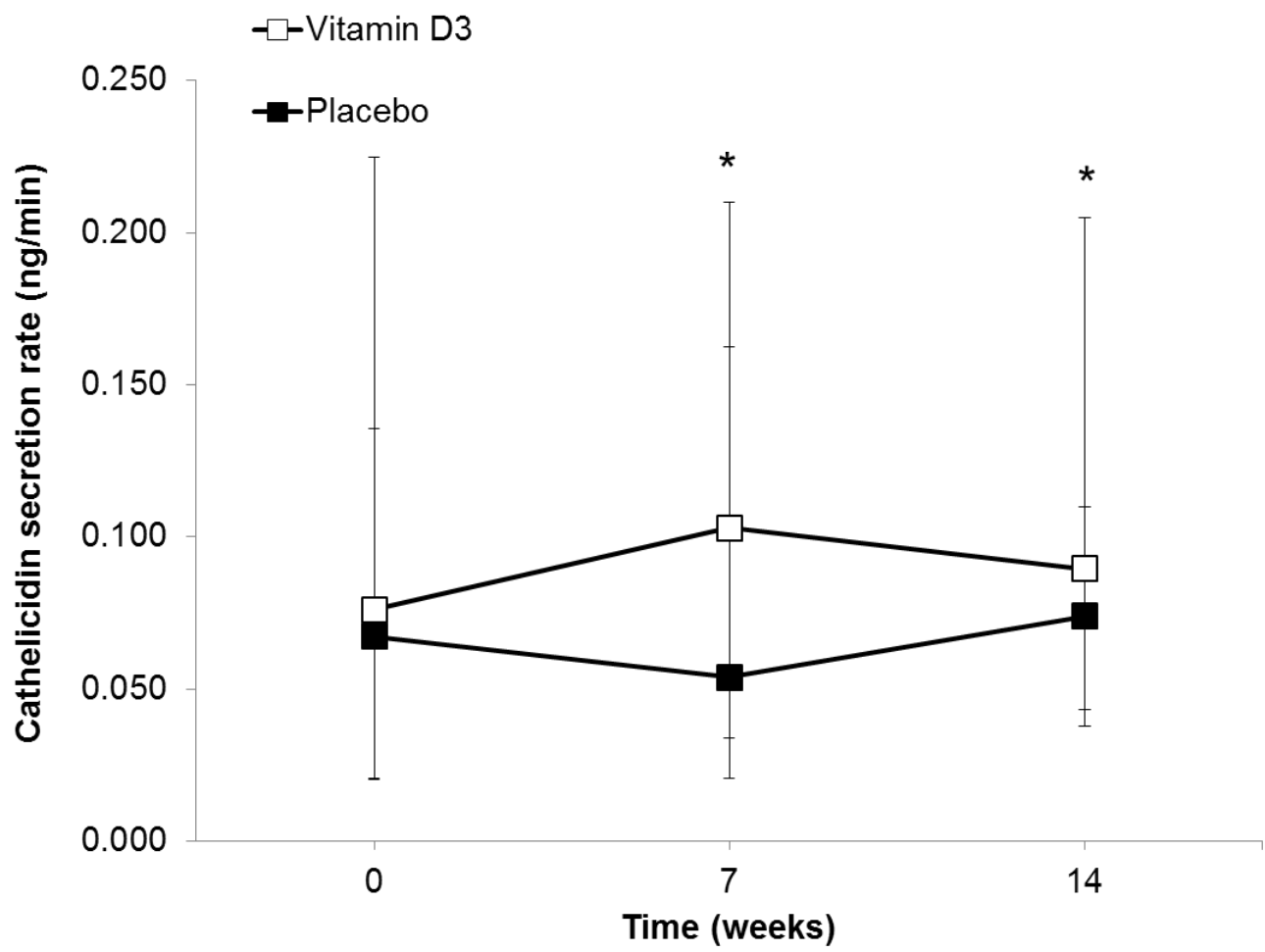


(C)

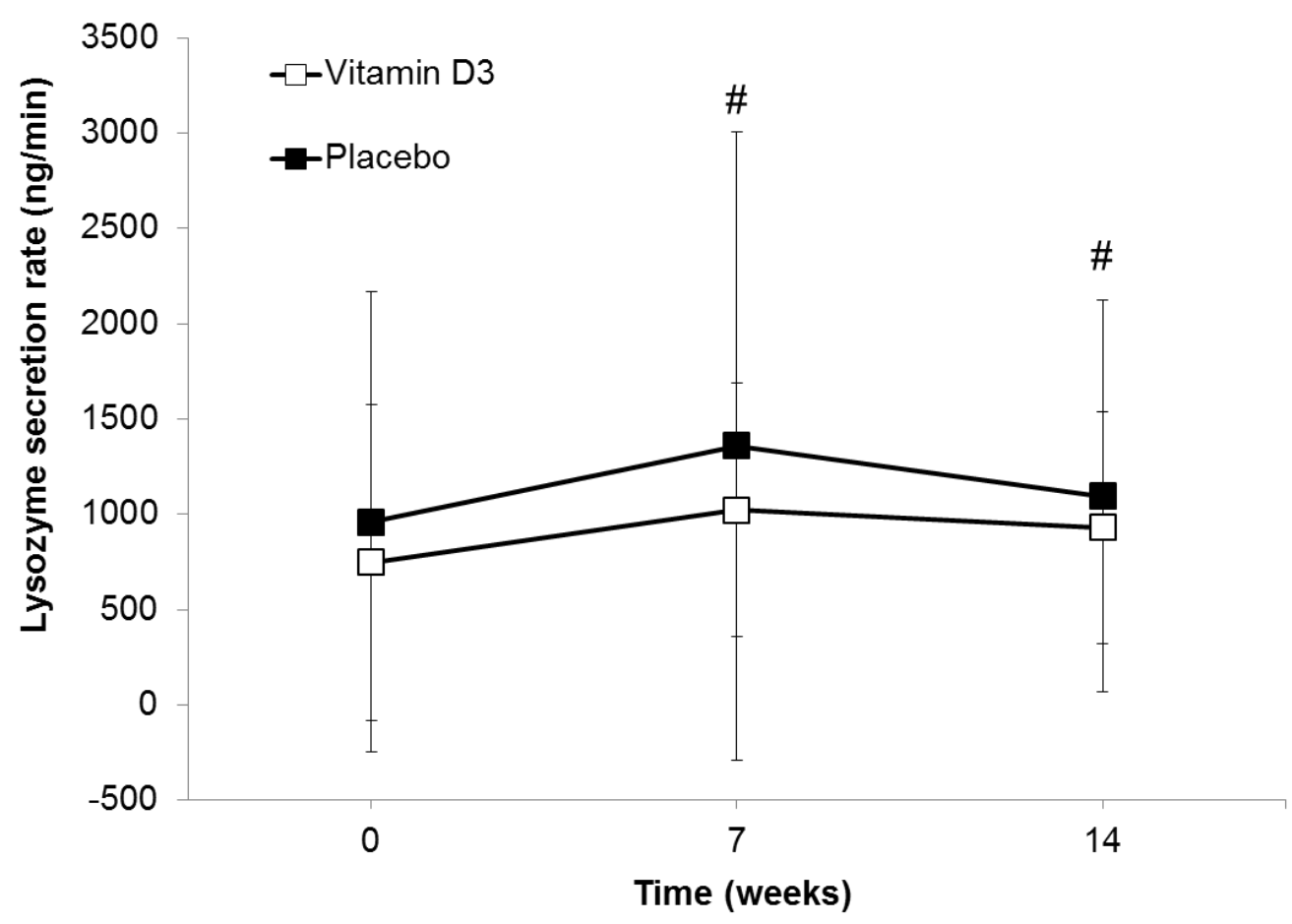

(D)

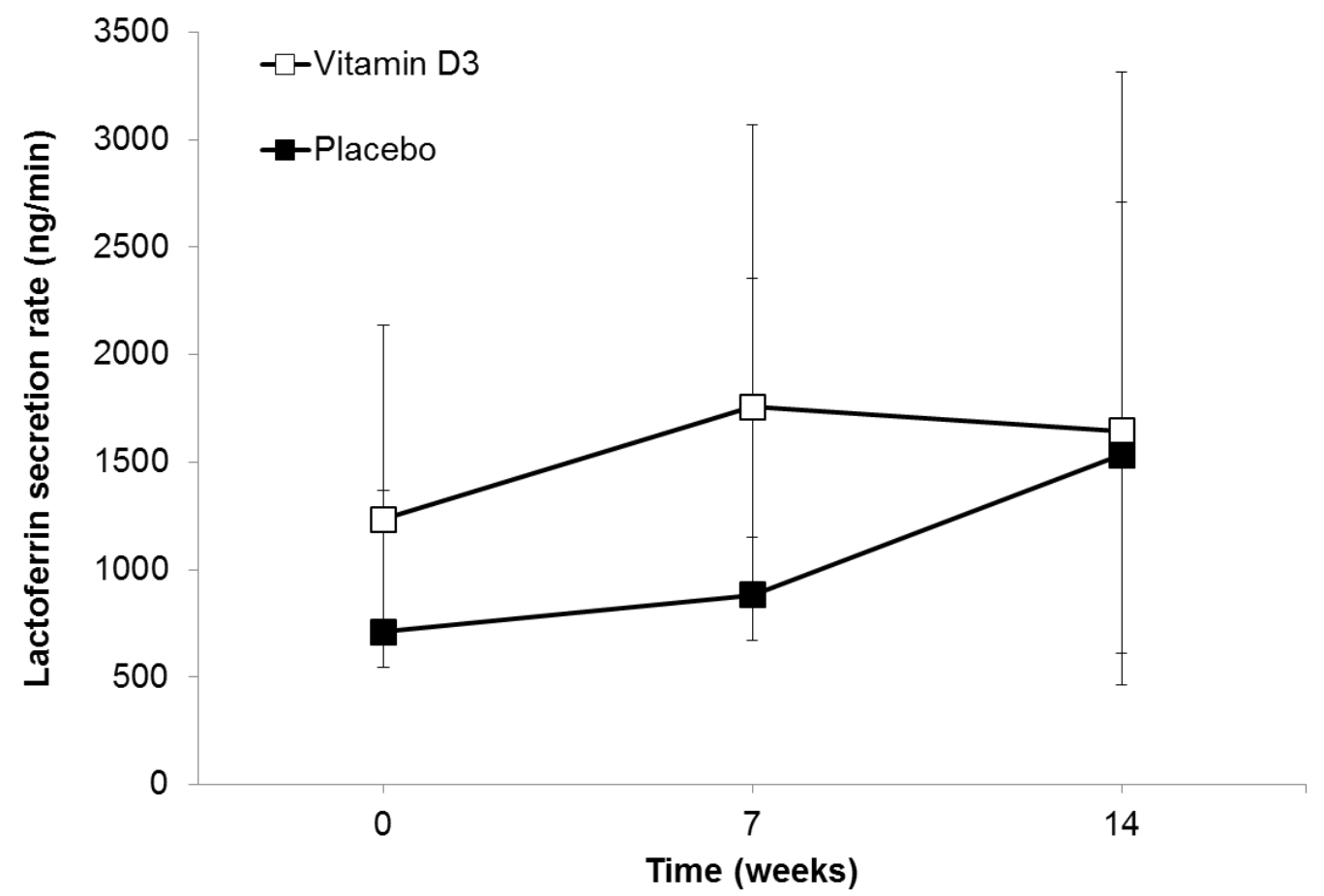

